\title{
Perhaps you should look at Art...
}

Harindra Karunatilake, Vajira Dharmawardene

There is a social cry for health workers, specially doctors to demonstrate more compassion. Ideal medical doctor should be both compassionate and competent. Though importance of compassion and related idea empathy is well recognized in healthcare, that both patients and doctors suffer when emphatic relationships between them are broken, they are rarely taught explicitly in healthcare disciplines. ${ }^{1}$

Can empathy be taught? Can learning make you compassionate? These questions have been discussed by academics in early childhood education to medical curriculum development world over. Broadly there have been formal approaches and more informal humanities based approaches to teach empathy. ${ }^{2}$

Many medical schools in United States now either require or offer elective courses that incorporate literature, film, and art to address the many facets of patient and caregiver experiences that are outside the field of medical science. Drawing, as well as creative and reflective writing has been incorporated into optional or required healthcare training. These provide opportunities for creative expression and foster observation and selfanalysis.

In Harvard medical school in Boston application of visual arts in medicine is called the "Training the Eye". In this programme students spend an afternoon a week in the museum with an art educator looking, reading and studying art. "There are some things that looking at art teaches us that apply very directly to taking care of patients," says Alexa Miller, creator of this novel teaching tool. ${ }^{3}$ Students are to look at a work of art, describe what they see and discuss with the group about their observations and compare each other's "findings". 4,5 The expectation is by making all kinds of observations and being asked to think about why they're seeing what they see, students will become more flexible thinkers who can hold different possibilities in their heads before making a diagnosis. ${ }^{5,6}$

There is evidence for art observation interventions improving diagnostic skills. Students who take "Training the Eye" are able to make nearly 40 percent more clinical observations than those who haven't taken the course. ${ }^{7}$
Studying art make you observe more objectively. Take the example of Giorgione's "Tempest". It takes time and careful observation to notice and appreciate all the subtle clues, obscure symbols and the complex expressions of the subjects. Understanding the meaning and interpreting the hidden messages of the artist is a different "art" itself.

"Mr and Mrs Andrews" by Gainsborough gives so many details to a keen observer. Clothes the subjects wear give clues to their financial status. This is very much evident in the Jan Vanmeers's "Girl with a Pearl Earring". Girl in the picture is a wearing a headdress something a servant would wear, indeed a clue to the social status of the subject.

By looking reading and studying art might make you more compassionate. Looking at faces of the subjects and trying to analyse their feelings at the time, attempting to relate to their backgrounds might help you to develop a more compassionate impression of the subjects. . Da Vinci's Monalisa, Vanmeers "Girl with a Pearl Earring", Jan Van Eyck's The Arnolfini portrait are few examples. With the trained eye one will be more engaging with the emotional narrative of the patient and be more open to their perspective.

Spending time in museum helps to improve observation skills. Standing before a carved sarcophagus from 350 B.C, one can feel the unspeakable magnitude of death and dying many times better than a textbook ever could. 4

What do these trends in medical education means to us in Sri Lanka? With plenty of clinical materials and a willingly participating patient population horning your observatory skills, looking at inanimate art may sound a waste of time. Visual arts have power to elicit an emotional response in the observer while making a student observe more objectively. This has been recognized as a useful empathy promoting endeavor. A case could be made to use visual arts in medical education. Even though looking at art may not seem the most essential part in a medical teaching, perhaps you should start looking at art when usual theories, data and facts start to bore you.

\section{Consultant Physician \\ 2 Consultant Psychiatrist District General Hospital Matara}

iD https://orcid.org/0000-0002-8306-2594

This is an open-access article distributed under the terms of the Creative Commons Attribution License, which permits unrestricted use, distribution and reproduction in any medium, provided the original author and source are credited. 


\section{References}

1. Jayasinghe $\mathrm{S}$. Integrating compassion to clinical care: a review of an emerging 'science'. Ceylon Journal of Medical Science 54(1):3-8 (2017)

2. Kelm Z, Womer J, Walter JK, Feudtner C. Interventions to cultivate physician empathy: a systematic review. BMC Medical Education. 2014; 14:219. doi: 10.1186/1472-6920-14-219.

3. Kowalczyk L. Monet? Gauguin? Using art to make better doctors. Boston Globe. July 20, 2008

4. Dolev JC, Friedlaender LK, Braverman IM. Use of fine art to enhance visual diagnostic skills. JAMA. 2001 Sep 5;286(9):1020-1.
5. Shapiro J, Rucker L, Beck J. Training the clinical eye and mind: using the arts to develop medical students' observational and pattern recognition skills. Med Educ. 2006 Mar;40(3):263-8.

6. Anderson RC, Fagan MJ, Sebastian J. Teaching students the art and science of physical diagnosis. Am J Med. 2001 Apr 1;110(5):419-23.

7. Naghshineh S, Hafler JP, Miller AR, et al. Formal Art Observation Training Improves Medical Students' Visual Diagnostic Skills. Journal of General Internal Medicine. 2008;23(7):991-997. doi:10.1007/s11606008-0667-0. 